\title{
Adolescent Mothers' Relationship With Their Children's Biological Fathers: Social Support, Social Strain, and Relationship Continuity
}

\author{
Christina B. Gee \\ George Washington University
}

\author{
Jean E. Rhodes \\ University of Massachusetts, Boston
}

\begin{abstract}
Two-hundred and eighteen low-income, minority, adolescent mothers were interviewed during the perinatal period and 3 years later about their social networks, including their relationships with their children's fathers. Few adolescents were involved with fathers at both time points. Relationships with fathers were, in general, less supportive and less problematic over time. Moreover, although father support was not associated with adolescent mothers' psychological adjustment, father absence and father strain had negative associations with psychological adjustment. Maternal grandmother support buffered the negative effects of strain in the adolescents' relationships with biological fathers. Perceptions of less social support from maternal grandmothers and more social support from fathers during the perinatal period as well as less social support from a new male partner at 3 years postpartum predicted relationship continuity between adolescent mothers and fathers at 3 years postpartum. Implications for intervention and policy are discussed.
\end{abstract}

In the United States, close to half a million adolescents give birth each year, but only $16 \%$ will marry before their child is born (Child Trends, 2001). Over the past decade, statistics such as these have increased attention, particularly among those interested in social policy, on the fathers of children born to adolescent mothers. ${ }^{1}$ Reflecting this interest in fathers, the 1996 Personal Responsibility and Work Opportunity Reconciliation Act placed an increased emphasis on establishment of paternity and strengthening child support efforts, effectively increasing fathers' involvement in the lives of adolescent mothers and their children (Coley \& Chase-Lansdale, 1998). For example, women receiving public assistance who fail to cooperate with the establishment of paternity can have their monthly cash aid reduced. Similarly, many states have initiated policies pertaining to the establishment of paternity and enforcement of child support.

Christina B. Gee, Department of Psychology, George Washington University; Jean E. Rhodes, Department of Psychology, University of Massachusetts, Boston.

This study was completed with the assistance of grants to Jean Rhodes from the William T. Grant Foundation, the National Institute of Child Health and Human Development, and the Office of Research on Women's Health. This study was also supported by an American Psychological Association Minority Fellowship to Christina B. Gee.

We gratefully acknowledge the assistance of Mark Aber, James Cordova, Jose Gomez-Lopez, Sara Gulbrandsen, Wendy Haight, Jewell Hamilton-Leaks, Kate Hellenga, Reed Larson, Joseph Pleck, Ranjini Reddy, Ryan Watkins, and the students at the alternative school.

Correspondence concerning this article should be addressed to Christina B. Gee, Department of Psychology, George Washington University, 2125 G Street, NW, Washington, DC 20052. E-mail: cgee@gwu.edu
Given this recent attention to paternity, research that attempts to understand the role of fathers in the lives of adolescent mothers is necessary. To this end, we conducted a study that addressed three central questions. First, how does support and strain in adolescent mothers' relationships with the fathers of their children change over the first 3 years postpartum? Second, what are the factors that predict relationship continuity over the first 3 years postpartum? Third, does father support and strain predict adolescent mothers' psychological adjustment? And, if so, does maternal grandmother support serve as a protective factor?

\section{Background}

The transition to motherhood represents a major developmental milestone for all women but is particularly stressful for adolescents. At the same time that they are struggling to negotiate their new, maternal roles and responsibilities, they are coping with the physical, emotional, and cognitive challenges of adolescence. Moreover, African American mothers often face additional adversities stemming from racial oppression and economic hardship. Chronic and isolated periods of economic hardship can be demoralizing to young, low-income, minority mothers and, not surprisingly, rates of depression are high in this population (Belle, 1994). For example, Hobfoll, Ritter, Lavin, Hulsizer, and Cameron (1995) found that $23.4 \%$ of low-income, urban, African American and European American mothers reported symptoms of postpartum depression, a rate that is double that found in middle-class samples (Cutrona, 1983; Gotlib, Whiffen, Wallace, \& Mount, 1991; O'Hara, 1986). Further, for low-income, African American and Puerto Rican adolescent mothers, these depressive symptoms have been

\footnotetext{
${ }^{1}$ In the current study, unless otherwise specified, "father" refers to the biological fathers of children born to adolescent mothers.
} 
shown to endure chronically or intermittently for at least 3 years postpartum (Leadbeater \& Linares, 1992).

Social support, particularly from adolescents' mothers and male partners, appears to play an important role in mitigating the postpartum adjustment difficulties (Leadbeater \& Bishop, 1994; McLoyd, 1990). Because minority young mothers are more likely than older mothers to be living in poverty they often rely heavily on others for child care, material assistance, and support. Yet, as their reliance on others increases, so too does their vulnerability to the problematic aspects of social relationships and depression (Davis \& Rhodes, 1994). Disputes about appropriate parenting and the young women's lifestyle can easily arise in the sharing of childrearing responsibilities (Davis, 2002; Davis, Rhodes, \& Hamilton-Leaks, 1997), and disappointment and frustration with male partners is not uncommon (Gee \& Rhodes, 1999). Moreover, young mothers with limited resources often find it difficult to reciprocate the support that they have received, creating an uncomfortable imbalance in the relationship (Belle, 1981), Indeed, MillerLoncar, Erwin, Landry, Smith, and Swank (1998) found that lower SES mothers were less satisfied with their social networks, and relative to other ethnic groups, African American mothers had more stressful social interactions with their network members. These and other findings (e.g., Davis, et al., 1997; Taylor, Henderson, \& Jackson, 1991) suggest that low-income, urban African American mothers' heightened exposure to life stressors may undermine the potential benefits of social support. Of course, there is likely to be considerable variation in African American mothers' experiences in their social networks and the support and benefits that they derive. For example, some young mothers benefit greatly from the support that is provided by the father of their babies and, more generally, their social networks. Indeed, many are embedded in rich kinship networks (Snowden, 2001; Stack, 1974), and many African American families are embedded in extensive, family, neighborhoodand church-based support networks (Wilson et al., 1995). Additional within-group research is needed to better understand the conditions under which support from key providers is available (and beneficial) to African American mothers.

\section{Father Involvement}

Male partners (including fathers) are one of the primary social resources to adolescent mothers, and the support that they provide during the postpartum adjustment period is often critical to the adolescents' well-being (Colletta, Hadler, \& Gregg, 1981; de Anda \& Becerra, 1984; Stack, 1974). Approximately half of adolescent mothers identify a male partner as someone who provides social support (e.g., Gee \& Rhodes, 1999; Thompson, 1986; Thompson \& Peebles-Wilkins, 1992), and this support is often rated as being as important as support provided by their mothers (de Anda \& Becerra, 1984; Gee \& Rhodes, 1999; Spieker \& Bensley; 1994; Thompson \& Peebles-Wilkins, 1992). Several cross-sectional studies suggest that the child's father and maternal grandmother provide approximately equal amounts of support throughout pregnancy and early motherhood (de Anda \& Becerra; 1984; Spieker \& Bensley; 1994; Thompson \& Peebles-Wilkins, 1992). Moreover, their support has been associated with adolescent mothers' greater overall life satisfaction (Unger \& Wandersman, 1988), lower psychological distress (Thompson, 1986; Thompson \& Peebles-Wilkins, 1992), and higher levels of self-esteem (Thompson \& Peebles-Wilkins, 1992). Furthermore, evidence suggests that father support may contribute to less angry and punitive parenting on the part of adolescent mothers (Crockenberg, 1987).

Other studies, however, present a less positive view of father support. Father support has been associated with diminished parenting skills (Shapiro \& Mangelsdorf, 1994) and reduced academic achievement for African American and European American adolescent mothers (Unger \& Cooley, 1992). Adolescent mothers often cite problems with their male partners ranging from disappointment over unmet expectations for financial and child care assistance to serious conflicts, difficult break-ups, and physical and sexual assault (Belle, 1981; Leadbeater \& Linares, 1992; Leadbeater \& Way, 2001; Leadbeater, Way, \& Raden, 1996). These problems in relationships with fathers, in turn, have been associated with heightened depressive symptoms among adolescent mothers (Gee \& Rhodes, 1999).

Taken together, the studies cited above suggest that male partners influence young mothers' psychological adjustment. In some cases, they provide support and comfort, whereas in others they contribute to distress and heightened adjustment difficulties. Despite their potential influence, few studies have provided detailed examinations of their role in adolescent mothers' lives.

Clarifying the association between father involvement and adolescent mothers' psychological adjustment is important for several reasons. As stated above, research has found high rates of depression among low-income, minority mothers (e.g., Belle, Doucet, Harris, Miller, \& Tan, 2000). Maternal stress and depression can take a toll on young mothers' parenting skills; depressed adolescent mothers have been rated as less competent in their parenting of infants than their nondepressed counterparts (Gelfand, Teti, \& Fox, 1992). They have been found to exhibit more negative and intrusive touch (Malphurs, Raag, Field, Pickens, \& PelaezNogueras, 1996), more controlling and less responsive interactions (Cassidy, Zoccolillo, \& Hughes, 1996; Downey \& Coyne, 1990), and more negative feeding interactions with their infants (Panzarine, Slater, \& Sharps, 1995).

As might be expected, exposure to poverty and maternal depression put children of adolescent mothers at disproportionate risk for cognitive impairment, social-emotional problems, and early and pervasive school failure (Belle et al., 2000). Leadbeater and Bishop (1994), for example, have documented robust associations between minority adolescent mothers' depression and their reports of preschool children's behavior problems over time. Moreover, the incidence of developmental delay and behavior problems in these children increases as they get older (Furstenberg, Brooks-Gunn, \& Morgan, 1987). For these reasons, it is critical that we understand the associations between 
father involvement and adolescent mother psychological adjustment.

A first step toward this end is for research on fathers to include more detailed assessments of father involvement. Most of the existing research and corresponding policy has focused on fathers' financial contributions, relying largely on census reports of child support payments. Nonetheless, qualitative studies have found that financial contributions to adolescent mothers may be higher than reported by the census because of irregular or unreported contributions (Coley \& Chase-Lansdale, 1998; Stier \& Tienda, 1993). Thus, this focus on financial support is incomplete, given the range of potentially influential types of support that fathers provide. In addition, many studies have included only global indices of support (e.g., satisfaction), and few have looked at social strain (e.g., criticism, disappointment) and its influence (Rook, 1990, 1998).

\section{Continuity of Father Involvement}

Despite the apparent importance of fathers in adolescent mothers' lives, these relationships appear to weaken over time (Rivara, Sweeny, \& Henderson, 1986). For example, adolescent mothers report that support from their male partners (i.e., boyfriends, biological fathers) decreases over the first postpartum year (Gee \& Rhodes, 1999; Wasserman, Brunelli, \& Rauh, 1990). In addition, during the course of the first couple of years postpartum, some adolescent mothers remain in romantic relationships with fathers whereas others terminate these relationships. For example, Unger and Wandersman (1988) reported that 50\% of African American adolescent mothers in their study were no longer involved with their child's father, and $40 \%$ had a new boyfriend at 8 months postpartum. Comparable rates of father involvement (51\% involved at 18 months postpartum) were found in a study of predominantly lower income, European American adolescent mothers (Cutrona, Hessling, Bacon, \& Russell, 1998). Further, Leadbeater and Way's (2001) longitudinal study of low-income, inner-city, minority mothers indicated that although $26 \%$ of adolescent mothers reported close (defined as frequent and emotionally positive contact) relationships with their child's father at 3 years postpartum, this percentage declined to $12 \%$ at 6 years postpartum.

Studies that document the decline of father involvement over time have prompted researchers to begin to study factors that predict continuous involvement on the part of the father. A growing body of research suggests the quality of the father's relationship with the mother early on in the pregnancy is an important predictor of continuity. Cutrona et al.'s (1998) study of lower income, European American adolescent mothers found that fathers were more likely to remain involved if their relationship with the adolescent mother was intimate and supportive during the weeks immediately following the baby's birth. Similarly, Gavin et al. (2002) found that, among low-income, urban, African American mothers, the strongest predictor of father involvement during the postpartum period was the quality of his relationship with his baby's mother. Also supporting these findings, Coley and Chase-Lansdale (1999) found that, regardless of romantic involvement, a strong or harmonious relationship with mothers increased the likelihood of urban African American fathers' involvement with their children.

Along the same vein, the formation of a romantic relationship with a new male partner may also affect the likelihood of continued father involvement. Again, the research is mixed on this issue. Whereas some research suggests that biological fathers may become less involved when new partners are involved (Cutrona et al., 1998), other research has found that new partners do not necessarily deter fathers from providing support (Coley \& Chase-Lansdale, 1999). Additional research examining predictors of romantic relationship continuity among adolescent mothers is clearly necessary.

Finally, another potentially important influence on the longevity of the adolescent mother-father relationship is the child's maternal grandmother. ${ }^{2}$ Maternal grandmothers sometimes serve as gatekeepers, or regulatory agents, who can either facilitate or prevent fathers from seeing adolescent mothers (Furstenberg, 1995). In support of the gatekeeping hypothesis, Gavin et al. (2002) found that fathers of children born to African American adolescent mothers were more involved when maternal grandmothers reported positive relationships with fathers.

\section{Maternal Grandmother Support}

Most previous studies have not examined the child's father and maternal grandmother simultaneously; thus, the interaction between maternal grandmother support and father strain has not been examined. The protective influence of close family members may be especially salient for African American adolescent mothers who often continue to live at home after the birth of their baby (e.g., Apfel \& Seitz, 1996; Chase-Lansdale, Gordon, Coley, Wakschlag, \& Brooks-Gunn, 1999; Unger \& Wandersman, 1988; Wasserman et al., 1990). Co-residence is particularly likely for African American adolescent mothers, who are often embedded in extensive networks of kinship support (Stack, 1974). Indeed, even when living apart, young African American mothers often obtain considerable help from immediate and extended family members (Apfel \& Seitz, 1991), and for approximately half of low-income, African American adolescent mothers, a significant amount of parenting support from their mothers continues until 6 years postpartum (Apfel \& Seitz, 1996).

Although some studies suggest that maternal grandmothers can be a source of strain (Belle, 1981; Bogat, Caldwell, Guzman, Galasso, \& Davidson, 1998; Rhodes \& Woods, 1995), research consistently indicates that grandmothers' support is positively associated with adolescent mothers' psychological well-being, academic attainment, financial status, disciplinary practices, and responsive mothering behavior (Cooley \& Unger, 1991; Spieker \& Bensley, 1994;

\footnotetext{
${ }^{2}$ In the current study, unless otherwise specified, maternal grandmother refers to the mother of the adolescent mother.
} 
Unger \& Cooley, 1992). Further, qualitative research indicates that receipt of financial and child care support from the maternal grandmother is associated with greater educational achievement (Cooley \& Unger, 1991; Furstenberg, BrooksGunn, \& Morgan, 1987) and better psychological wellbeing for adolescent mothers (e.g., Panzarine, 1986).

\section{Summary}

The existing research suggests that, at least initially, fathers are involved in the lives of adolescent mothers and their children and that their influence has costs and benefits. In light of their potential influence, as well as the policies that promote long-term involvement, it is important to identify factors that predict relationship continuity. Unfortunately, despite some notable exceptions (e.g., Furstenberg \& Harris, 1993; Leadbeater \& Way, 2001), the majority of the research specifically examining father involvement is crosssectional and tends to be collected only immediately postpartum. Given the limitations of cross-sectional data, it is unclear how adolescent mothers' relationships with fathers change over time and what factors predict continued involvement.

\section{Goals of the Current Study}

The present study was designed to examine the role of biological fathers in the lives of minority adolescent mothers over the first 3 years postpartum. On the basis of the existing literature, we had several hypotheses. First, we hypothesized that fathers' support and strain would diminish during the first 3 years postpartum as compared with the perinatal period. Second, we hypothesized that adolescent mothers with higher levels of father social support during the perinatal period, lower levels of maternal grandmother support, higher levels of maternal grandmother strain, and less support from a new male partner would be more likely to have continuous involvement from their baby's father over the first 3 years postpartum. Third, we hypothesized that high maternal grandmother support would attenuate the negative impact of father strain on adolescent mothers' psychological well-being (i.e., depression and anxiety).

\section{Method}

\section{Procedure}

During the 1992-1993 academic year, all students $(N=378)$ attending an alternative school for pregnant and parenting adolescents, located in a large midwestern city, were invited to participate in the study. A research associate explained to the students and their parents that participation was voluntary and confidential and obtained informed consent. Most (94\%) of the students agreed to participate and received $\$ 10$ for each interview. The initial (Time 1) interviews took place at the school and the 3 years postpartum (Time 2) interviews took place either at school, in their homes, or by telephone. Interviews of the African American students were conducted by a female, African American research associate in a master's degree program in social work. A Latina postdoctoral student conducted the interviews with the Latina students.

\section{Participants}

Only students who completed both interviews $(62 \% ; N=233)$ and who did not have significant missing data were included in the following analyses $(58 \% ; N=218)$. The participants were predominantly African American (95\%), with a small percentage of Hispanic/Latina participants (5\%). Racial/ethnic background information was not available for 1 participant.

At the Time 1 (T1) interview, participants had a mean age of 15.9 years $(S D=1.33)$, ranging from 13 to 19 years old. The majority of participants (64\%) were receiving some form of public assistance. Almost half (47\%) relied on public aid as their primary source of income and $42 \%$ relied on their parents. Almost none $(99 \%)$ of the participants had ever been married and most were either pregnant $(58 \%)$ or had recently given birth to their first child (38\%) at the time of initial interview. The remaining $4 \%$ had recently given birth to their second child.

At Time 2 (T2), $43 \%$ of the participants had one child, $45 \%$ had two children, $10 \%$ had three children, and $2 \%$ had four children. Most of the adolescent mothers remained unmarried at T2 (95\%). Only $28 \%$ of the participants were currently employed. Over half $(59 \%)$ relied on public aid as their primary source of income, $19 \%$ relied on their own jobs, $9 \%$ relied on their parents, and 5\% relied on a male partner. Although more than half of the participants (58\%) had not completed high school, many participants had achieved some level of academic success. Specifically, a sizable percentage of the participants $(18 \%)$ had earned a high school diploma, an even greater percentage $(21 \%)$ had partially completed college, and notably 1 participant (1\%) had completed a college degree.

Analyses were conducted to examine potential attrition biases. There were no significant differences at T1 between the follow-up group and the attrition group on age, number of children, depression, or anxiety. Further, there were no significant differences between the follow-up group and the attrition group on levels of social support, the numbers of persons perceived as available to provide the various types of support, overall network size, or the levels of social strain. The only significant group difference found was that the attrition group was more likely to have received public aid at $\mathrm{T} 1,\left(\chi^{2}(1, N=378)=5.14, p<.05\right)$.

\section{Measures}

Demographic information. Information regarding participants' age, race, marital status, parity, pregnancy status, and receipt of public assistance was obtained through a set of fixed format questions. Some additional information regarding fathers was available at $\mathrm{T} 2$ but not at T1. At T2, all adolescent mothers provided demographic information (i.e., age, highest level of education, and current occupation) about their child's father. Further, at T2, all adolescent mothers were asked about their current romantic involvement with and frequency of contact with their child's father. The father of the child with whom the adolescent mother was pregnant during her enrollment at the alternative school was selected as the target father for the current study. Fathers' occupational prestige was coded in accordance with Stevens and Cho's (1985) socioeconomic index (SEI), which assigns scores to specific occupations on the basis of a combination of prestige and income. After removal of two extreme outliers, the mean SEI score was $22.19(S D=4.41)$ for employed fathers, which is approximately equivalent to the occupations of "cashier" or "motor transportation occupation."

Social support and social strain. The Social Support Network Questionnaire (SSNQ; Rhodes, Meyers, Davis, Ebert, \& Gee, 2003), a modification and extension of the Arizona Social Support Interview Schedule (Barrera, 1981), was used to assess adolescent mothers' self-reported social support and social strain. Seven types 
Table 1

Means and Standard Deviations of Social Support and Strain Variables for Social Network Members of Adolescent Mothers

\begin{tabular}{|c|c|c|c|c|c|c|c|c|}
\hline \multirow[b]{3}{*}{ Variable } & \multicolumn{2}{|c|}{ Father } & \multicolumn{2}{|c|}{ Maternal grandmother } & \multicolumn{2}{|c|}{ Paternal grandmother } & \multicolumn{2}{|c|}{$\begin{array}{c}\text { Boyfriend } \\
\text { (not target baby's father) }\end{array}$} \\
\hline & $\mathrm{T} 1$ & $\mathrm{~T} 2$ & $\mathrm{~T} 1$ & $\mathrm{~T} 2$ & $\mathrm{~T} 1$ & $\mathrm{~T} 2$ & $\mathrm{~T} 1$ & $\mathrm{~T} 2$ \\
\hline & $M(S D)$ & $M(S D)$ & $M(S D)$ & $M(S D)$ & $M(S D)$ & $M(S D)$ & $M(S D)$ & $M(S D)$ \\
\hline EMO & $0.61(1.12)$ & $0.27(0.79)$ & $1.25(1.27)$ & $0.97(1.22)$ & $0.00(0.29)$ & $0.01(0.34)$ & $0.14(0.59)$ & $0.48(1.07)$ \\
\hline COG & $0.56(1.03)$ & $0.29(0.83)$ & $1.66(1.29)$ & $1.29(1.28)$ & $0.10(0.51)$ & $0.12(0.52)$ & $0.17(0.65)$ & 0.54 (1.09) \\
\hline POS & $0.85(1.23)$ & $0.35(0.88)$ & $1.60(1.22)$ & $1.37(1.26)$ & $0.15(0.61)$ & $0.01(0.44)$ & $0.18(0.66)$ & $0.62(1.13)$ \\
\hline $\mathrm{SOC}$ & $1.16(1.39)$ & $0.45(1.02)$ & $1.10(1.30)$ & $0.80(1.21)$ & $0.11(0.53)$ & $0.12(0.54)$ & $0.27(0.83)$ & $0.85(1.32)$ \\
\hline TAN & $0.97(1.33)$ & $0.42(1.00)$ & $1.94(1.26)$ & $1.54(1.32)$ & $0.11(0.54)$ & $0.01(0.42)$ & $0.24(0.77)$ & $0.62(1.14)$ \\
\hline PRG & $0.73(1.22)$ & $0.00(0.43)$ & $1.41(1.38)$ & $0.16(0.66)$ & $0.14(0.58)$ & $0.02(0.24)$ & $0.16(0.65)$ & $0.11(0.55)$ \\
\hline $\mathrm{CHC}$ & $0.48(1.08)$ & 0.55 (1.09) & $0.86(1.29)$ & $1.67(1.35)$ & $0.13(0.60)$ & $0.19(0.69)$ & $0.11(0.55)$ & $0.57(1.10)$ \\
\hline $\mathrm{CON}$ & $0.99(1.37)$ & $0.57(1.15)$ & $0.96(1.27)$ & $0.95(1.19)$ & $0.00(0.28)$ & $0.00(0.25)$ & $0.22(0.75)$ & $0.70(1.24)$ \\
\hline INT & $0.90(1.37)$ & 0.59 (1.27) & $1.71(1.57)$ & $1.65(1.61)$ & $0.10(0.56)$ & $0.13(0.60)$ & $0.20(0.75)$ & $0.88(1.52)$ \\
\hline DIS & $0.81(1.20)$ & $0.52(1.10)$ & $1.06(1.22)$ & $0.90(1.04)$ & $0.01(0.47)$ & $0.01(0.32)$ & $0.17(0.64)$ & $0.50(1.00)$ \\
\hline CRT & $0.25(0.78)$ & $0.22(0.69)$ & $0.45(0.99)$ & $0.48(1.08)$ & $0.00(0.17)$ & $0.00(0.29)$ & $0.01(0.32)$ & $0.70(1.24)$ \\
\hline
\end{tabular}

Note. $\quad N=218 . \mathrm{EMO}=$ emotional support $\mathrm{COG}=$ cognitive guidance; $\mathrm{POS}=$ positive feedback; $\mathrm{SOC}=\mathrm{socializing} ; \mathrm{TAN}=$ tangible assistance, $\mathrm{PRG}=$ pregnancy-related support; $\mathrm{CHC}=$ child care support; $\mathrm{CON}=$ conflict; INT $=$ intrusiveness; DIS = disappointment; $\mathrm{CRT}=$ criticism .

of social support (emotional, tangible assistance, cognitive guidance, positive feedback, socializing, pregnancy-related assistance, and child care) were assessed. Participants were first asked to name all individuals who would be available for a particular type of social support. For example, "If you wanted to talk to someone about something personal or private, who would you talk to-for instance, if you had something on your mind that was worrying you or making you feel down?" Participants could nominate up to 40 individuals to their social network. Next, the interviewer asked participants to indicate, on a four-point scale ranging from 0 (never) to 3 (more than once a week), how frequently they actually derived each type of support from the individuals during the past month. For example, "During the past month, how often did you actually talk to each of these people about something personal or private?" Later on in the interview, participants were asked, in an open-ended format, to state their relation to each person in their social network (e.g., mother, baby's father).

Total support scores were derived for each individual on the social network, representing the sum of support scores across all types of support. ${ }^{3}$ Participants also rated, on a 5-point scale ranging from 0 (never) to 4 (always), how often each network member was a source of four types of social strain: conflict, criticism, intrusiveness, and disappointment. Participants could add individuals to the social network who were not initially nominated as sources of support. Thus, individuals were considered nominated on the participants' social networks if they were perceived as a source of either support or strain. When an individual was not nominated on the network, the support and strain variables were given the values corresponding to never for support and strain.

For some of the analyses, the entire sample was included, regardless of whether or not the participants nominated their baby's father on the network. In these analyses, a score of 0 was entered for the support and strain variables for those adolescent mothers who did not nominate the father. For other analyses, only the subsample that nominated the baby's father was included. We conducted these analyses in order to assess the effects of different levels of father support and strain among those adolescent mothers who actually had some contact with their baby's father.

The internal consistencies of the father support and strain items were high at both $\mathrm{T} 1(\alpha \mathrm{s}=.91$ and .84 , respectively) and T2 ( $\alpha \mathrm{s}$ $=.92$ and .88 , respectively). The internal consistencies conducted on father support and strain for the subsample that nominated the father on their network were slightly lower, but adequate, at both $\mathrm{T} 1(\alpha \mathrm{s}=.79$ and .72 , respectively $)$ and $\mathrm{T} 2(\alpha \mathrm{s}=.80$ and .65, respectively).

Psychological functioning. The 13-item depression and 10item anxiety subscales of the Symptom Checklist-90-Revised (SCL-90-R; Derogatis, 1983) were used to assess psychological functioning. The items were presented in mixed order to reduce response bias. The alphas for depression in the current study were .84 and .91 at $\mathrm{T} 1$ and $\mathrm{T} 2$, respectively; the alphas for anxiety were .80 and .89 at $\mathrm{T} 1$ and $\mathrm{T} 2$, respectively. The mean total score was $12.8(S D=8.8)$ for the Depression subscale and $6.2(S D=5.7)$ for the Anxiety subscale. The correlations between scores on the Anxiety and Depression subscales were $r=.74$ at T1 and $r=.83$ at $\mathrm{T} 2$.

\section{Results}

\section{Adolescent Mothers' Social Networks}

Adolescent mothers nominated a mean of 5.7 individuals $(S D=2.37)$ on their social networks at $\mathrm{T} 1$ (range $=1$ to 17$)$ and a mean of 4.8 individuals $(S D=2.28)$ at $\mathrm{T} 2$ (range $=$ 1 to 15$)$. At T1, maternal grandmothers and fathers were nominated most frequently, with $86 \%$ of the participants nominating their mothers and $51 \%$ nominating fathers. At T2, maternal grandmothers remained the most frequently nominated individuals $(76 \%)$; however, fathers were nominated by only $27 \%$ of participants, behind best friends $(44 \%)$ and new male partners (36\%). Table 1 indicates the

\footnotetext{
${ }^{3}$ At $\mathrm{T} 1$, this sum includes pregnancy-related support but not child care support because most adolescents had not given birth to their child at the time of the interview. At T2, this sum includes child care support but not pregnancy support because most adolescents had not recently been pregnant. Interpretations of associations among individual support or strain types and outcomes should be tempered by the understanding that measures of different kinds of social support tend to be highly correlated.
} 
Table 2

Means and Standard Deviations of Social Support and Strain Variables for Subsamples Nominating Individuals on Social Network

\begin{tabular}{|c|c|c|c|c|c|c|c|c|}
\hline \multirow[b]{3}{*}{ Variable } & \multicolumn{2}{|c|}{ Father } & \multicolumn{2}{|c|}{ Maternal grandmother } & \multicolumn{2}{|c|}{ Paternal grandmother } & \multicolumn{2}{|c|}{$\begin{array}{c}\text { Boyfriend } \\
\text { (not target baby's father) }\end{array}$} \\
\hline & $\mathrm{T} 1(n=110)$ & $\mathrm{T} 2(n=159)$ & $\mathrm{T} 1(n=188)$ & $\mathrm{T} 2(n=165)$ & $\mathrm{T} 1(n=25)$ & $\mathrm{T} 2(n=19)$ & $\mathrm{T} 1(n=26)$ & $\mathrm{T} 2(n=79)$ \\
\hline & $M(S D)$ & $M(S D)$ & $M(S D)$ & $M(S D)$ & $M(S D)$ & $M(S D)$ & $M(S D)$ & $M(S D)$ \\
\hline EMO & $1.22(1.33)$ & $98(1.27)$ & $1.45(1.26)$ & $1.28(1.25)$ & $0.36(0.81)$ & $0.53(1.07)$ & $1.19(1.33)$ & $1.33(1.43)$ \\
\hline COG & $1.10(1.23)$ & $1.07(1.31)$ & $1.92(1.19)$ & $1.70(1.20)$ & 0.88 (1.27) & $0.95(1.22)$ & $1.42(1.33)$ & $1.49(1.36)$ \\
\hline POS & $1.69(1.25)$ & $1.29(1.29)$ & $1.86(1.12)$ & $1.81(1.14)$ & $1.32(1.31)$ & $1.42(1.26)$ & $1.50(1.30)$ & $1.72(1.29)$ \\
\hline SOC & 2.30 (1.09) & $1.66(1.37)$ & $1.27(1.32)$ & $1.05(1.28)$ & $0.92(1.32)$ & $0.79(1.23)$ & $2.23(1.17)$ & $2.34(1.13)$ \\
\hline TAN & $1.92(1.29)$ & $1.56(1.38)$ & $2.24(1.08)$ & $2.03(1.14)$ & $1.00(1.29)$ & $1.37(1.21)$ & $2.00(1.23)$ & $1.71(1.31)$ \\
\hline PRG & $1.45(1.39)$ & $0.25(0.80)$ & $1.63(1.36)$ & $0.21(0.75)$ & $1.24(1.27)$ & $0.26(0.81)$ & $1.30(1.44)$ & $0.29(0.88)$ \\
\hline $\mathrm{CHC}$ & $0.96(1.36)$ & $2.03(1.17)$ & $0.99(1.34)$ & $2.21(1.11)$ & $1.16(1.43)$ & $2.21(1.03)$ & $0.88(1.37)$ & $1.57(1.33)$ \\
\hline $\mathrm{CON}$ & $1.96(1.34)$ & $2.10(1.30)$ & $1.10(1.30)$ & $1.26(1.22)$ & $0.40(0.76)$ & $0.53(0.70)$ & $1.81(1.39)$ & $1.92(1.38)$ \\
\hline INT & $1.79(1.46)$ & $2.15(1.60)$ & $1.98(1.52)$ & $2.18(1.51)$ & $0.88(1.45)$ & $1.53(1.47)$ & $1.69(1.49)$ & $2.42(1.64)$ \\
\hline DIS & $1.60(1.26)$ & $1.93(1.31)$ & $1.22(1.23)$ & $1.19(1.04)$ & $0.84(1.14)$ & $0.79(0.79)$ & $1.42(1.30)$ & $1.38(1.24)$ \\
\hline CRT & $0.49(1.04)$ & $0.80(1.14)$ & $0.52(1.05)$ & $0.64(1.12)$ & $0.16(0.47)$ & $0.37(0.96)$ & $0.50(0.81)$ & $0.75(1.20)$ \\
\hline
\end{tabular}

Note. $\quad$ EMO $=$ emotional support $\mathrm{COG}=$ cognitive guidance; POS $=$ positive feedback; SOC $=$ socializing; TAN $=$ tangible assistance; $\mathrm{PRG}=$ pregnancy-related support $\mathrm{CHC}=$ child care support; $\mathrm{CON}=$ conflict; INT $=$ intrusiveness; DIS $=$ disappointment; $\mathrm{CRT}=$ criticism.

mean levels of support and strain for fathers, maternal grandmothers, paternal grandmothers, and boyfriends regardless of nomination on the social network (when not nominated, these individuals are scored as a zero). Table 2 indicates the mean levels of support and strain for these individuals only when they are nominated on the social network.

\section{Demographic Characteristics of Fathers}

Time 1. The vast majority (95\%) of adolescent mothers had not had children with men other than the target father. At T1, data on fathers were only available when the adolescent mother nominated him on her social network $(51 \%$; $n=110)$. Most of the adolescent mothers who nominated fathers on their social networks at T1 were romantically involved with them (94\%), although only $2 \%$ were married to them. Adolescent mothers saw nominated fathers at least a few times a week (92\%); only a few (1\%) saw them less than once a month. Only a small percentage (12\%) coresided with fathers. At T1, nominated fathers were between 15 and 29 years old $(M=18.8, S D=2.3)$, and the mean age gap between adolescent mothers and nominated fathers was 2.7 years $(S D=2.6)$, ranging from 2 years younger to 16 years older than adolescent mothers. ${ }^{4}$

Time 2. At 3 years postpartum, $21 \%(n=46)$ of the adolescent mothers were romantically involved with the fathers although only $2 \%(n=5)$ were married to them. At $\mathrm{T} 2$, the majority of the adolescent mothers $(63 \%)$ had children exclusively with the target fathers $(66 \%$ had one child, $30 \%$ had two children, and $4 \%$ had three children with the fathers). A very small percentage $(2 \% ; n=4)$ of adolescent mothers had children with more than one other man. Fortyfour percent of the adolescent mothers saw the fathers at least a few times a week, but $27 \%$ did not see him at all.

Slightly more than one quarter $(27 \% ; n=59)$ of the adolescent mothers nominated fathers on their social net- works at T2. The majority $(63 \% ; n=37)$ of nominated fathers were romantically involved with the adolescent mothers. However, similar to the pattern for the entire sample, only a small percentage $(n=4 ; 11 \%)$ of those romantic relationships involved marriage. Most of the adolescent mothers $(85 \%)$ saw nominated fathers at least a few times a week. Forty-one percent of those who nominated the father as a network member were living with him.

At T2, fathers were reported to be between the ages of 17 and 34 years $(M=22.0 ; S D=2.8)$. According to the adolescent mothers, partial high school was the highest level of education attained for almost half (47\%) of the fathers, high school diplomas for approximately one third $(32 \%)$, and partial college $(13 \%)$ or college degrees $(1 \%)$ had been completed by a few fathers. Approximately one third (32\%) of the fathers were reported to be employed; almost half $(49 \%)$ of fathers were reported to be unemployed. Some fathers were not employed because they were incarcerated $(7 \%)$, in school $(1 \%)$, or deceased $(2 \%)$. Nine percent of the adolescent mothers had no knowledge of the father's employment situation.

\section{Changes in Social Support and Social Strain}

A repeated measures multivariate analysis of variance (MANOVA) was used to examine the changes in support and strain over the first 3 years postpartum. The data met the assumptions of normality and homogeneity of variance for a repeated measures MANOVA. Change in father's childcare support and pregnancy support were not examined because at $\mathrm{T} 1$ most adolescent mothers were pregnant (thus child care was not needed) and at T2 most adolescents were not pregnant (thus pregnancy support was not needed).

\footnotetext{
${ }^{4}$ At T2, the mean age gap between adolescent mothers and all fathers (including those not nominated) was $2.76(S D=2.79$; range $=-2$ to 18 ).
} 
Table 3

Univariate Tests on Support and Strain for the Entire Sample

\begin{tabular}{ccc}
\hline Variable & $F(1,217)$ & $p$ \\
\hline EMO & 16.64 & $<.01$ \\
COG & 11.52 & $<.01$ \\
POS & 30.23 & $<.01$ \\
SOC & 45.06 & $<.01$ \\
TAN & 33.72 & $<.01$ \\
CON & 14.20 & $<.01$ \\
INT & 6.72 & $<.05$ \\
DIS & 7.11 & $<.01$ \\
CRT & 0.21 & $n s$
\end{tabular}

Note. $\quad N=218$. EMO $=$ emotional support; $\mathrm{COG}=$ cognitive guidance; $\mathrm{POS}=$ positive feedback; $\mathrm{SOC}=$ socializing; TAN $=$ tangible assistance; $\mathrm{CON}=$ conflict; INT = intrusiveness; DIS = disappointment; CRT $=$ criticism.

First, changes in the amounts of reported social support and strain in relationships with fathers were examined with the entire sample $(N=218)$, regardless of the father's nomination on the SSNQ. Time served as the within-subject variable in this repeated measures MANOVA. As presented in Table 3 the results showed a main effect for time on support, Wilks's lambda $=.82 ; F(5,213)=9.68, p=.000$, and strain, Wilks's lambda $=.93 ; F(4,214)=4.27, p=$ .002 . As hypothesized, adolescent mothers' perceptions of the amounts of each type of father support decreased from T1 to T2. Disappointment, conflict, and intrusiveness decreased from $\mathrm{T} 1$ to $\mathrm{T} 2$; there were no significant differences for criticism.

Second, in order to address the possibility that the results of the above analysis were simply due to father absence, we repeated our analysis to examine changes in support and strain within the group of adolescent mothers who nominated fathers on their social networks at both $\mathrm{T} 1$ and $\mathrm{T} 2$ $(17 \% ; n=38)$. Within this analysis, in order to further explain our findings, we examined whether the father was also a romantic partner. Parallel repeated measures MANOVAs were conducted for each type of support and strain. Time served as the within-subject variable and ro- mantic partner status as the between-subjects variable. Romantic partner status at T2 was coded as a dichotomous variable, with $0=$ father was not romantic partner $(n=14)$ and $1=$ father was romantic partner $(n=24)$. Means are presented in Table 4.

For support, results indicated a significant Time $\times$ Romantic partner status interaction, Wilks's lambda $=.68$; $F(5,32)=3.01, p<.05$. Univariate tests indicated significant Time $\times$ Romantic partner status interactions for emotional support, cognitive guidance, and socializing (see Table 5). For these three types of support, fathers who were adolescent mothers' romantic partners at $\mathrm{T} 2$ provided more T2 support than those who were not the romantic partner. There were no significant differences at T1. Main effects of time were found for tangible assistance and positive feedback, with amounts of these types of support greater at T1 than $\mathrm{T} 2$.

For strain, results also indicated a significant Time $\times$ Romantic partner status interaction, Wilks's lambda $=.67$; $F(4,33)=4.17, p<.01$. Univariate tests indicated significant interactions for disappointment and criticism (see Table 5). Fathers who were not romantic partners at $\mathrm{T} 2$ were a greater source of disappointment and criticism at T2 (see Table 4 for means). There were no significant differences in disappointment and criticism at T1. Main effects of time were found for conflict and for intrusiveness (T1 greater than T2).

\section{Predictors of Continuous Relationships With Fathers}

Given the small number of adolescents $(17 \% ; n=38)$ who nominated fathers on their social networks at both T1 and $\mathrm{T} 2$, the predictors of relationship continuity were explored. A hierarchical logistic regression was conducted on the subsample of adolescent mothers who nominated fathers on their social network at T1 $(n=110)$. Two groups were created: (a) the continuous relationship group $(n=38)$, in which the father was nominated at both time points, and (b) the terminated relationship group $(n=72)$, in which the

Table 4

Descriptive Information for Social Support and Social Strain by Romantic Partner Status When the Father Is Nominated on the Network at Both Time 1 and Time 2

\begin{tabular}{|c|c|c|c|c|}
\hline \multirow[b]{3}{*}{ Variable } & \multicolumn{2}{|c|}{$\begin{array}{l}\text { Is romantic partner } \\
\text { at Time } 2(n=24)\end{array}$} & \multicolumn{2}{|c|}{$\begin{array}{l}\text { Is not romantic partner } \\
\text { at Time } 2(n=14)\end{array}$} \\
\hline & Time 1 & Time 2 & Time 1 & Time 2 \\
\hline & $\overline{M(S D)}$ & $\overline{M(S D)}$ & $\overline{M(S D)}$ & $M(S D)$ \\
\hline Emotional support & $1.3(1.4)$ & $1.5(1.3)$ & $1.6(1.4)$ & $0.4(1.0)$ \\
\hline Cognitive guidance & $1.4(1.2)$ & $1.7(1.4)$ & $1.6(1.2)$ & $0.7(1.1)$ \\
\hline Positive feedback & $2.0(1.1)$ & $1.5(1.3)$ & $2.1(1.1)$ & $1.3(1.1)$ \\
\hline Socializing & $2.6(0.9)$ & $2.2(1.2)$ & $2.6(0.6)$ & $0.9(1.0)$ \\
\hline Tangible assistance & $2.4(1.1)$ & $2.3(1.4)$ & $2.4(0.9)$ & $1.4(1.3)$ \\
\hline Conflict & $1.8(1.4)$ & $1.9(1.2)$ & $2.1(1.4)$ & $2.4(1.3)$ \\
\hline Intrusiveness & $1.5(1.4)$ & 1.9 (1.6) & $1.5(1.7)$ & $2.1(1.6)$ \\
\hline Disappointment & $1.5(1.0)$ & $1.3(1.2)$ & $1.4(1.2)$ & $2.8(1.0)$ \\
\hline Criticism & $0.4(0.9)$ & $0.4(0.8)$ & $0.4(0.6)$ & $1.6(1.4)$ \\
\hline
\end{tabular}


Table 5

Changes in Support for Subsample who Nominated Father on Network

\begin{tabular}{|c|c|c|c|c|c|c|c|c|c|}
\hline Variable & Emotional & $\begin{array}{l}\text { Cognitive } \\
\text { guidance }\end{array}$ & $\begin{array}{l}\text { Positive } \\
\text { feedback }\end{array}$ & Socializing & $\begin{array}{c}\text { Tangible } \\
\text { assistance }\end{array}$ & Conflict & Intrusiveness & Disappointment & Criticism \\
\hline $\begin{array}{l}\text { Time } \\
\text { Romantic }\end{array}$ & $3.0 \dagger$ & 1.32 & $5.01 *$ & $22.64 * *$ & $4.57 *$ & 0.74 & 2.08 & $5.60 *$ & $7.13^{*}$ \\
\hline $\begin{array}{l}\text { partner } \\
\text { status }\end{array}$ & 1.47 & 1.57 & 0.10 & $8.22 * *$ & $3.00 \dagger$ & 1.29 & 0.06 & $6.64 *$ & $7.50 *$ \\
\hline $\begin{array}{l}\text { Time } \times \\
\quad \text { Romantic } \\
\text { Partner }\end{array}$ & & & & & & & & & \\
\hline Status & $5.95 *$ & $4.84 *$ & 0.35 & $8.75^{* *}$ & $3.27 \dagger$ & 0.29 & 0.09 & $11.79 * *$ & $6.16^{*}$ \\
\hline
\end{tabular}

Note. Values presented are $F \mathrm{~s}$ (for univariate tests; $d f \mathrm{~s}=1,36$ ).

$\dagger p<.10$. $* p<.05$. ** $p<.01$.

father was nominated at T1 but not at T2. ${ }^{5}$ Demographic variables were entered in the first step, variables reflecting the quality of adolescent mothers' relationships with fathers at T1 were entered in the second step, T1 maternal grandmother support and strain in the third step, the father's age at T1 in the fourth step, the father's T2 occupational prestige in the fifth step, and adolescent mothers' T2 network characteristics (i.e., new male partner support, maternal grandmother support, and maternal grandmother strain) in the final step. Missing data for the occupational prestige variable resulted in 94 cases for analysis $(n=37$ for the continuous relationship group; $n=57$ for the terminated relationship group).

A test of the full model with all predictors against a constant-only model was significant, $\chi^{2}(12, N=94)=$ $41.00, p<.01$, indicating that the predictors, as a set, reliably distinguished between adolescent mothers in continuous relationships and those in terminated relationships. Prediction success was good, with $81 \%$ of all adolescent mothers correctly classified. Table 6 shows the regression coefficients, Wald statistics, and odds ratios for each predictor. According to the Wald criterion, two father variables predicted relationship continuity: the total amount of support from the father and his age (both at T1). As hypothesized, fathers who were more supportive at $\mathrm{T} 1$ were more likely to remain involved with adolescent mothers at $\mathrm{T} 2$; fathers who were older at $\mathrm{T} 1$ were also more likely to remain involved. Further, consistent with our hypothesis, the adolescent mother's relationship with her baby's maternal grandmother predicted relationship continuity. Specifically, adolescent mothers who had perceived less support from the child's maternal grandmother at $\mathrm{T} 1$ were more likely to be involved in continuous relationships at $\mathrm{T} 2$. Finally, also consistent with our hypothesis, lower levels of support from a new male partner were associated with a greater likelihood of relationship continuity between adolescent mothers and fathers.

\section{Associations of Father Support and Strain With Psychological Outcomes}

Hierarchical regression analyses were conducted on the full sample $(N=218)$ to investigate the associations between father social support, father social strain, mater- nal grandmother support, and adolescent mothers' psychological outcomes. Parallel regressions were conducted using depressive symptomatology and anxiety at $\mathrm{T} 2$ as the dependent variables. The adolescent mothers' level of depressive symptoms (or anxiety) at T1 was controlled for in the first step and adolescent mothers' demographic characteristics were controlled for in the second step. Maternal grandmother support and strain were entered in the third step in order to assess the contribution of fathers over and above maternal grandmothers. In addition, using the procedure recommended by Cohen and Cohen (1975) to handle missing data, we entered a dummy variable to assess contribution of maternal grandmother absence from the network at T2 $(0=$ present; $1=$ absent). Similarly, the fourth step included both variables for the level of perceived father support and strain and a dummy variable representing father absence from the network at $\mathrm{T} 2(0=$ present; $1=$ absent). The interaction terms were entered in the last two steps: Father Strain $\times$ Maternal Grandmother Support in the fifth step and Father Support $\times$ Maternal Grandmother Strain in the sixth step. All interactions were tested using centered data.

The regression analysis revealed significant interactions between father strain and maternal grandmother support on anxiety and depressive symptoms (see Table 7). Figures 1 and 2 illustrate graphical representations of these interactions. In addition to the interaction, several main effects emerged as well. First, maternal grandmother strain was significantly positively associated with depressive symptoms and marginally associated with anxiety. Second, father absence was positively associated with both depressive symptoms and anxiety. Contrary to our hypothesis, no main effect emerged for father support. The final model for depressive symptoms explained

\footnotetext{
${ }^{5}$ Twenty-one adolescent mothers nominated their baby's father at T2 but not at T1. Given the specific hypotheses of this study and the small group size, this group was not included in the analyses to predict relationship continuity.
} 
Table 6

Logistic Regression Predicting Relationship Continuity

\begin{tabular}{lcrc}
\hline \multicolumn{1}{c}{ Variable } & & & $\begin{array}{c}\text { Estimated } \\
\text { odds ratio } \\
\text { for } B\end{array}$ \\
\hline Step 1: Adolescent mother's age at T1 & $B$ & Wald & 0.11 \\
Step 2: Satisfaction with father support at T1 & 0.08 & 1.09 \\
Total amount of father support at T1 & 0.58 & 1.39 & 1.79 \\
Total amount of father strain at T1 & 0.11 & 4.60 & 1.22 \\
Step 3: Total amount of maternal grandmother support at T1 & $-0.16^{*}$ & 0.85 & 1.11 \\
Total amount of maternal grandmother strain at T1 & 0.06 & 0.78 & 0.85 \\
Step 4: Father's age at T1 & $0.37^{*}$ & 6.46 & 1.06 \\
Step 5: Father's occupational prestige at T2 & 0.03 & 2.55 & 1.04 \\
Step 6: New male partner support at T2 & $-0.25^{* *}$ & 10.31 & 0.78 \\
$\quad$ Maternal grandmother support at T2 & 0.12 & 2.99 & 1.12 \\
Maternal grandmother strain at T2 & 0.10 & 2.73 & 1.19 \\
\hline
\end{tabular}

Note. All statistics presented are after the final step. T1 $=$ Time $1 ; \mathrm{T} 2=$ Time $2 ;-2 \log$

likelihood $=84.19$; Nagelkerke $R^{2}=0.49$.

$* p<.05$. ** $p<.01$.

$33 \%$ of the variance, and the final model for anxiety explained $30 \%$ of the variance.

\section{Discussion}

The goal of the present study was to examine adolescent mothers' relationships with the fathers of their children perinatally and at 3 years postpartum. Consistent with previous studies, few adolescents were involved with fathers at both time points. Nine percent of the fathers were either incarcerated or deceased at 3 years postpartum. Relationships with fathers were, in general, less supportive and less problematic at 3 years postpartum than during the perinatal period. Results indicated that father support was not associated with adolescent mothers' psychological adjustment. Father absence, however, was positively associated with both depressive symptoms and anxiety. In addition, father strain had negative effects on psychological adjustment that were buffered by support from maternal grandmothers.

\section{Father Characteristics and Involvement}

During the perinatal period, adolescent mothers nominated maternal grandmothers on their social network most frequently and nominated fathers with the next highest frequency. However, by 3 years postpartum, adolescent mothers still nominated maternal grandmothers most frequently, but fathers became less prominent and were nominated less frequently than best friends and new male partners. Consistent with previous research, adolescent mothers' perceptions of the amount of support and strain in their relationships with fathers decreased over time. Decreases across all types of positive and negative interactions may be explained by the sheer decrease in contact between adolescent mothers and fathers. Among those in continuous relationships, decreases in emotional support, cognitive guidance, and socializing support were moderated by romantic involvement at 3 years postpartum. Not surprisingly,

Table 7

Hierarchical Multiple Regressions Predicting Adolescent Mothers' Depressive Symptoms and Anxiety at Time 2

\begin{tabular}{|c|c|c|}
\hline Variable & $\begin{array}{c}\text { Depressive } \\
\text { symptoms } \\
(N=218)\end{array}$ & $\begin{array}{c}\text { Anxiety } \\
(N=218)\end{array}$ \\
\hline Step 1: T1 level of dependent variable & $0.27 * *$ & $0.30 * *$ \\
\hline Step 2: Adolescent mother's T2 age & $-0.13 *$ & -0.05 \\
\hline Adolescent mother's T2 number of children & 0.02 & -0.04 \\
\hline Received public assistance at T2 & 0.08 & $0.12 \dagger$ \\
\hline Step 3: Maternal grandmother T2 strain & $0.26 * *$ & $0.14 \dagger$ \\
\hline Maternal grandmother T2 support & 0.04 & $0.16 \dagger$ \\
\hline Maternal grandmother absence at $\mathrm{T} 2$ & 0.10 & 0.15 \\
\hline Step 4: Father T2 support & $0.22 \dagger$ & 0.20 \\
\hline Father T2 strain & $0.77 * *$ & $0.73 * *$ \\
\hline Father absence at $\mathrm{T} 2$ & $0.68 * *$ & $0.63 * *$ \\
\hline Step 5: Father T2 Strain $\times$ Maternal Grandmother T2 Support & $-0.27 * *$ & $-0.26 *$ \\
\hline Step 6: Father T2 Support $\times$ Maternal grandmother T2 Strain & 0.06 & 0.10 \\
\hline Total $R^{2}$ (adjusted) & $0.33(.27)$ & $0.30(.26)$ \\
\hline Overall $F(1,206)$ & $8.30 * *$ & $7.84 * *$ \\
\hline
\end{tabular}

Note. All regression coefficients $\left(R^{2} \mathrm{~s}\right)$ are from the final step. Receipt of public assistance was coded $0=$ did not receive, $1=$ received. $\dagger p<.10$. $* p<.05$. ** $p<.01$. 


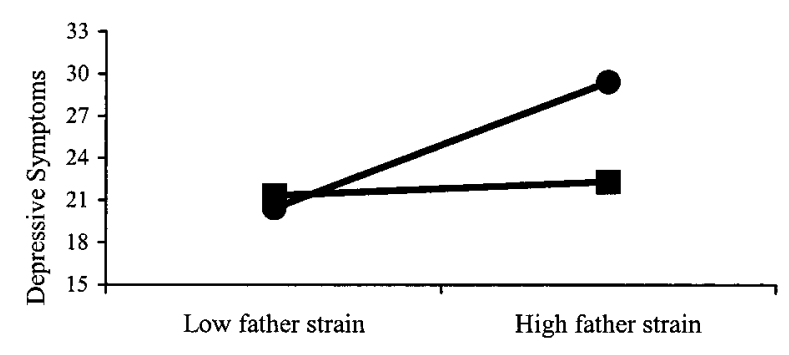

- Low maternal grandmother support

Figure 1. Father strain by maternal grandmother support interaction for depressive symptoms.

these types of support were most likely to be provided in the context of a romantic relationship.

\section{Relationship Continuity}

Approximately one fifth of the adolescent mothers had nominated the father on their network at both $\mathrm{T} 1$ and $\mathrm{T} 2$, and most of these continuing relationships were romantic in nature. Several factors were associated with relationship continuity (romantic or nonromantic) at 3 years postpartum. First, adolescent mothers in continuous relationships perceived fathers as more supportive during the perinatal period. A father's support of an adolescent mother during this period may have reflected his greater acceptance of the pregnancy, his personality (e.g., conscientiousness), and/or the strength of the adolescent mother-father relationship. Alternatively, involvement during the child's infancy may have promoted involvement through the formation of strong early parent-child attachments (Chase-Lansdale et al., 1999).

Another predictor of relationship continuity was a perceived lack of support from the child's maternal grandmother during the perinatal period. Adolescents who received less support from the maternal grandmother were more likely to maintain a relationship with the father. This finding is consistent with the findings of Pearson, Hunter, Ensminger, and Kellam (1990) suggesting that adolescent mothers' male partners may play a compensatory support role in the absence of maternal support. It is also possible, as several researchers have suggested, that mothers play a gatekeeping role (Allen \& Doherty, 1996; Lamb, 1986; Hetherington, Bridges, \& Insabella, 1998). In these situations, adolescent mothers who chose to be with the father may have forfeited their mother's support.

Finally, receiving support from a new romantic partner at 3 years postpartum was negatively associated with relationship continuity. Research indicates that the vast majority of children of adolescent mothers live with a nonbiological father figure for at least some period of time (Furstenberg \& Harris, 1993). It is possible that adolescent mothers who were involved with new male partners no longer desired support from their baby's father. Alternatively, fathers may have disengaged from adolescent mothers because of discomfort with visiting their children when the adolescent mothers were involved with a new male partner. It is also possible that the biological fathers no longer felt obligated to provide as much support if they believed that new partners were acting as a surrogate father to their children. Given the potential for new partners to serve as father figures, future research should examine their impact on both the adolescent mother and her child.

\section{Associations With Psychosocial Outcomes}

Surprisingly, father support was not associated with depressive symptoms or anxiety. However, father absence was associated with negative psychological outcomes. In addition, consistent with previous research, results suggest that maternal grandmothers were an important source of support. First, maternal grandmothers were the most frequently nominated individuals on adolescent mothers' social networks at both T1 and T2. Second, significant interactions suggest that maternal grandmother support may serve as a buffer against the negative psychological effects of strain in adolescent mothers' relationships with their children's fathers. That is, when maternal support was high, adolescent mothers reported the same level of depressive symptoms and anxiety regardless of the amount of father strain. Further, the depressive symptoms and anxiety were at their highest levels when adolescent mothers experienced a high amount of father strain in the context of little support from their mother. Maternal grandmothers should not, however, be viewed as a panacea, particularly in light of the associations between strain in that relationship and adolescent mothers' depressive symptomatology. This finding is consistent with previous literature indicating that problems in relationships with maternal grandmothers are associated with adolescent mothers' psychological distress (e.g., Davis \& Rhodes, 1994).

Of course, it is possible that the associations between maternal grandmother support and lower psychological distress can be explained by an unmeasured third variable. For example, a personality characteristic (e.g., optimism) may have resulted in both resiliency to depression and percep-

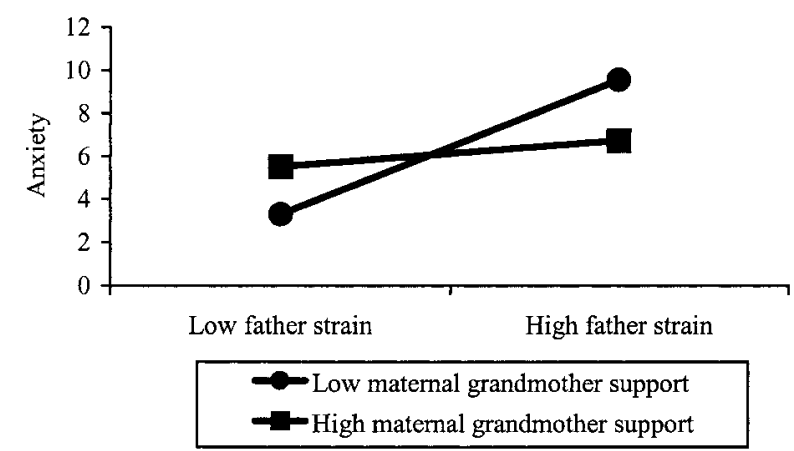

Figure 2. Father strain by maternal grandmother support interaction for anxiety. 
tions of more maternal grandmother support. Future research should also examine the role of the paternal grandparents as a potential buffer to the stress associated with early parenthood. Like the maternal grandmother, the paternal grandparents have an investment in the well-being of the child. Alternatively, social strain in relationships with paternal grandparents may exacerbate other stressors present in the adolescent mothers' life. Because only 19 participants reported significant involvement on the part of the paternal grandparents, we did not have enough power to statistically examine these associations.

\section{Limitations}

Any interpretations of these findings must be tempered with recognition of this study's limitations. There was a fairly high degree of attrition from the first interview to the follow-up interview, and analyses indicated that the more economically disadvantaged group was less likely to be retained. It is possible that the attrition sample differs from the follow-up sample in a variety of ways that were not or could not be assessed. For example, perhaps the attrition sample was more likely to have remained in relationships with their children's fathers. It should be noted, however, that our attrition rate is not unusual among studies of lowincome urban populations (e.g., Seidman, Allen, Aber, Mitchell, \& Feinman, 1994). Researchers should try to develop strategies for better tracking these populations to improve the generalizability of research findings in the future.

Another limitation of the present study is its reliance on self-report measures. Although adolescent mothers' reports of their relationships with their mothers tend to converge with independent observers (Gonzales, Cauce, \& Mason, 1996), future research in this area might also conduct behavioral observations of adolescents' social interactions as well as include maternal grandmothers' and fathers' perceptions of their relationships with adolescent mothers. In addition, the SSNQ did not include questions specifically concerning the father; thus, it is possible that these data do not capture minor and sporadic incidents of support and strain occurring more than 1 month ago. However, it is arguable that given the numerous opportunities on the SSNQ for the adolescent mothers to mention their child's father, if he was not mentioned, then it is likely that his involvement was not significant to her at the present time.

Finally, the results of this study may not generalize to other groups of pregnant and parenting adolescents. All of the participants were initially attending an alternative school for pregnant and parenting adolescents, all were young women of color, and most came from poor families. Studies should determine whether the same pattern of findings emerge with pregnant and parenting adolescents of differing socioeconomic and cultural backgrounds. The protective role that maternal support plays on father strain may differ depending on the family's ethnicity and socioeconomic status (Miller-Loncar, et al., 1998). One might expect that the adolescent mother's extended family plays a particularly strong role in both the African American and Latino com- munities given the importance placed on families in these cultures (de Anda, 1984; Stack, 1974). For example, for African American adolescent mothers who can rely on an extended kinship network for support (Tolson \& Wilson, 1990; Stack, 1974), father support may be less important to their well-being than for their European American counterparts. In contrast, less acculturated Latina adolescent mothers who are more likely to be married than their more acculturated Latina counterparts (de Anda \& Becerra, 1984) may rely more heavily on father support. Furthermore, factors such as neighborhood and socioeconomic status might also affect fathers' attitudes and behavior toward their children (Sullivan, 1989). Future studies should examine the cultural contexts that may affect the influence and meaning of father support across diverse populations.

\section{Implications for Application and Public Policy}

Despite these limitations, this study contributes to our knowledge of minority adolescent mothers' lives and has several implications for theory and research. First, the differences demonstrated across types of support and strain suggest the importance of taking a fine-tuned analysis when studying social support. By expanding the study of social support beyond both narrow conceptions (e.g., financial support) and extremely global conceptions of support (e.g., support satisfaction) social support theorists can come to a better, albeit more complicated, understanding of father involvement in adolescent mothers' and their children's lives.

Second, these findings highlight the importance of considering social support in an ecological context. This research emphasizes the importance of including adolescent mothers' broader social networks (i.e., grandmother, new partners) when trying to understand their relationships with fathers. Future research should explore other network members besides grandmothers whose support may also play a protective role for adolescent mothers. In addition, this research emphasizes the importance of considering neighborhood-level variables. The alarming percentage of young fathers who were deceased or incarcerated speaks to the dangers that exist within the communities in which many adolescent mothers and their children live (see Achatz \& MacAllum, 1994; Larson, Hussey, Gillmore, \& Gilchrist, 1996; Whitman, Borkowski, Keogh, \& Weed, 2001). Finally, this study highlights the importance of tracking support over time. Future research that examines adolescent mother-father relationships over a longer period of time would increase our understanding of the evolution of these relationships.

The current study also has implications for intervention. Interventions should be designed in order to support fathers in finding employment that pays a sufficient wage for them to provide for their families. Further, in light of the maternal grandmothers' protective role, interventions such as mutual support groups should be designed to further assist them. This study also points to the potential need for interventions that support the adolescent mothers' relationship with the biological father during the transition to parenthood. Indeed, 
the results of this study are consistent with early findings from the Fragile Families Study indicating that fatherhood programs are more likely to be successful if they are targeted toward fathers during the perinatal period and before the relationship with the adolescent mother has terminated (McLanahan \& Carlson, 2002).

The results of this study also have implications for policies related to child support enforcement. Currently, the child support system has concentrated on strengthening enforcement efforts by increasing paternity identification and locating "deadbeat" dads. These efforts often target adolescent mothers in hopes that they will provide the name and address of their child's father. Requiring mothers to provide information to help locate the father can create an antagonistic relationship between the parents (McLanahan $\&$ Carlson, 2002) and may serve to further alienate the father. Further, child support enforcement efforts, in the absence of employment assistance for fathers, may result in fathers attempting to evade arrest, thus having even less contact with their children (for a review of welfare policies relevant to fathers, see Bernard, 1998). The Parents Fair Share program is one program that shows initial promise in helping low-income noncustodial fathers to make consistent child support payments and increase their involvement with their children by helping them to find more stable jobs with better wages (Miller \& Knox, 2001). Leadbeater (1998) has argued that funds that are spent on child support enforcement could be better spent on policies that assist fathers in finding adequate employment.

Further, the existing child support policies provide little incentive for fathers to acknowledge paternity because when the recipients are on welfare, in most states, the majority of the child support payment is taken by the state to offset welfare costs (Bernard, 1998; Miller \& Knox, 2001). Policies that provide incentives to fathers for paternity establishment may assist fathers in solidifying their commitment to adolescent mother and their child and thus foster their continued involvement throughout their child's life.

Finally, the current welfare policy allows states the option of making the paternal grandparents responsible for child support payments if the father is a minor and living with them (Bernard, 1998). Policies such as this may lead parents and grandparents to push young fathers out of the home. More research should be conducted in order to understand the impact of the loss of paternal grandparent support on fathers in order to prevent unintended negative consequences. Given that many fathers have difficulty obtaining satisfactory employment and completing schooling, support from their parents may be critical during this transition period. States must carefully consider the ramifications of these and other policies affecting adolescent mothers, fathers, and their children in order to prevent unintended negative consequences. In addition, policies that offer public assistance incentives to adolescents who reside with or marry their babies' biological fathers may be misguided given the instability and strife that appear inherent in these ties. It may not be in the best interest of adolescent mothers to sustain relationships that are not supportive or would not otherwise remain intact.

\section{Conclusion}

In conclusion, this study adds to our understanding of the complexity of adolescent mothers' relationships with the men who are the fathers of their children. These findings highlight the importance of examining these relationships within an ecological context that includes the opportunity structure as well as more proximal factors such as other adolescent mothers' relationships with the child's maternal and paternal grandparents. Understanding the complex interplay of these factors will contribute to a more nuanced understanding of how minority adolescent mothers cope with their stressful life circumstances.

\section{References}

Achatz, M., \& MacAllum, C. A. (1994). Young unwed fathers: Report from the field. Philadelphia: Public Private Ventures.

Allen, W. D., \& Doherty, W. J. (1996). The responsibilities of fatherhood as perceived by African-American teenage fathers. Families in Society: The Journal of Contemporary Human Services, 77, 142-155.

Apfel, N. H., \& Seitz, V. (1991). Four models of adolescent mother-grandmother relationships in Black inner-city families. Family Relations: Interdisciplinary Journal of Applied Family Studies, 40, 421-429.

Apfel, N. H., \& Seitz, V. (1996). African American adolescent mothers, their families, and their daughters: A longitudinal perspective over twelve years. In B. J. Leadbeater \& N. Way (Eds.), Urban girls: Resisting stereotypes, creating identities. (pp. 149172). New York: New York University Press.

Barrera, M. (1981). Social support in the adjustment of pregnant adolescents: Assessment issues. In B. H. Gottlieb (Ed.), Social networks and social support. (pp. 69-96). Beverly Hills, CA: Sage.

Belle, D. (1981, April). The social network as a source of both stress and support to low-income mothers. Paper presented at the biennial meeting of the Society for Research on Child Development, Boston.

Belle, D. (1994). Attempting to comprehend the lives of lowincome women. In C. E. Franz \& A. J. Stewart (Eds.), Women creating lives: Identities, resilience, and resistance (pp. 37-50). Boulder, CO: Westview Press.

Belle, D., Doucet, J., Harris, J., Miller, J., \& Tan, E. (2000). Who is rich? Who is happy? American Psychologist, 55, 1160-1161.

Bernard, S. (1998). Responsible fatherhood and welfare: How states can use the new law to help children. New York: National Center for Children in Poverty.

Bogat, G. A., Caldwell, R. A., Guzman, B., Galasso, L., \& Davidson, W. S. (1998). Structure and stability of maternal support among pregnant and parenting adolescents. Journal of Community Psychology, 26, 549-568.

Cassidy, B., Zoccolillo, M., \& Hughes, S. (1996). Psychopathology in adolescent mothers and its effects on mother-infant interactions: A pilot study. Canadian Journal of Psychiatry, 41, 379-384.

Chase-Lansdale, P. L., Gordon, R. A., Coley, R. L., Wakschlag, L., \& Brooks-Gunn, J. (1999). Young African-American multigenerational families in poverty. The contexts, exchanges, and processes of their lives. In E. M. Hetherington (Ed.), Coping with 
divorce, single parenting, and remarriage: A risk and resiliency perspective. Mahwah, NJ: Erlbaum.

Child Trends. (2001). Facts at a glance. Washington, DC: Author. Cohen, J., \& Cohen, P. (1975). Applied multiple regression/ correlation analysis for the behavioral sciences. Hillsdale, NJ: Erlbaum.

Coley, R. L., \& Chase-Lansdale, P. L. (1998). Adolescent pregnancy and parenthood: Recent evidence and future directions. American Psychologist, 53, 152-166.

Coley, R. L., \& Chase-Lansdale, P. L. (1999). Stability and change in paternal involvement of urban African-American fathers. Journal of Family Psychology, 13, 416-435.

Colletta, N. D., Hadler, S., Gregg, C. H. (1981). How adolescents cope with the problems of early motherhood. Adolescence, 16, 499-512.

Cooley, M. L., \& Unger, D. G. (1991). The role of family support in determining developmental outcomes in children of teen mothers. Child Psychiatry and Human Development, 21, 217233.

Crockenberg, S. B. (1987). Predictors and correlates of anger toward and punitive control of toddlers by adolescent mothers. Child Development, 58, 964-975.

Cutrona, C. E. (1983). Causal attributions and perinatal depression. Journal of Abnormal Psychology, 92, 161-172.

Cutrona, C. E., Hessling, R. M., Bacon, P. L., \& Russell, D. W. (1998). Predictors and correlates of continuing involvement with the baby's father among adolescent mothers. Journal of Family Psychology, 12, 369-387.

Davis, A. A. (2002). Younger and older African American adolescent mothers' relationships with their mothers and female peers. Journal of Adolescent Research, 17, 491-508.

Davis, A. A., \& Rhodes, J. E. (1994). African-American mothers and their mothers: An analysis of supportive and problematic interactions. Journal of Community Psychology, 22, 12-20.

Davis, A. A., Rhodes, J. E., \& Hamilton-Leaks, J. (1997). When both parents may be a source of support and problems: An analysis of pregnant and parenting female African American adolescents' relationships with their mothers and fathers. Journal of Research on Adolescence, 7, 331-348.

de Anda, D. (1984). Informal support networks of Hispanic mothers: A comparison across age groups. Journal of Social Service Research, 7, 89-105.

de Anda, D., \& Becerra, R. M. (1984). Social support networks for adolescent mothers. Journal of Social Casework, 65, 172-181.

Derogatis, L. R. (1983). SCL-90-R: Administration, scoring, and procedures manual-II. Baltimore: Clinical Psychometric Research.

Downey, G., \& Coyne, J. C. (1990). Children of depressed parents: An integrative review. Psychological Bulletin, 108, 50-76.

Furstenberg, F. F., Jr. (1995). Fathering in the inner city: Paternal participation and public policy. In W. Marsiglio (Ed.), Fatherhood: Contemporary theory, research, and social policy. London: Sage.

Furstenberg, F. F., Brooks-Gunn, J., \& Morgan, S. P. (1987). Adolescent mothers in later life. Cambridge, England: Cambridge University Press.

Furstenberg, F. F., \& Harris, K. M. (1993). When and why fathers matter: Impacts of father involvement on the children of adolescent mothers. In A. Lawson \& D. Rhodes (Eds.), The politics of pregnancy (pp. 189-215). New Haven, CT: Yale University Press.

Gavin, L. E., Black, M. M., Minor, S., Abel, Y., Papas, M. A., \& Bentley, M. E. (2002). Young, disadvantaged fathers' involve- ment with their infants: An ecological perspective. Journal of Adolescent Health, 31, 266-276.

Gee, C. B., \& Rhodes, J. E. (1999). Postpartum transitions in adolescent mothers' romantic and maternal relationships. Merrill-Palmer Quarterly, 45, 512-532.

Gelfand, D. M., Teti, D. M., \& Fox, C. R. (1992). Sources of parenting stress for depressed and nondepressed mothers of infants. Journal of Clinical Child Psychology, 21, 262-272.

Gonzales, N. A., Cauce, A. M., \& Mason, C. A. (1996). Interobserver agreement in the assessment of parental behavior and parent-adolescent conflict: African American mothers, daughters, and independent observers. Child Development, 67, 14831498.

Gotlib, I. H., Whiffen, V. E., Wallace, P. M., \& Mount, J. H. (1991). Prospective investigation of post-partum depression: Factors involved in onset and recovery. Journal of Abnormal Psychology, 100, 122-132.

Hetherington, E. M., Bridges, M., \& Insabella, G. M. (1998). What matters? What does not? Five perspectives on the association between marital transitions and children's adjustment. American Psychologist, 53, 167-184.

Hobfoll, S., Ritter, C., Lavin, J., Hulsizer, M. R., \& Cameron, R. P. (1995). Depression prevalence and incidence among inner-city pregnant and postpartum women. Journal of Consulting and Clinical Psychology, 63, 445-453.

Lamb, M. E. (1986). The father's role: Applied perspectives. New York: Wiley.

Larson, N. C., Hussey, J., Gillmore, M., \& Gilchrist, L. (1996). What about dad? Fathers of children born to school-age mothers. Families in Society, 77, 279-289.

Leadbeater, B. J. (1998). The goals of welfare reform reconsidered: Supporting the transition to work for inner-city adolescent mothers. Children's Services: Social Policy, Research, and Practice, 2, 23-44.

Leadbeater, B. J., \& Bishop, S. J. (1994). Predictors of behavior problems in preschool children of inner-city Afro-American and Puerto Rican adolescent mothers. Child Development, 65, 638648.

Leadbeater, B. J., \& Linares, O. (1992). Depressive symptoms in Black and Puerto Rican adolescent mothers in the first three years postpartum. Development and Psychopathology, 4, 451468.

Leadbeater, B. J., \& Way, N. (2001). Growing up fast: Transitions to early adulthood of inner-city adolescent mothers. Mahwah, NJ: Erlbaum.

Leadbeater, B. J. R., Way, N., \& Raden, A. (1996). Why not marry your baby's father? Answers from African-American and Hispanic adolescent mothers. In B. J. R. Leadbeater \& N. Way (Eds.), Urban girls: Resisting stereotypes, creating identities. New York: New York University Press.

Malphurs, J. E., Raag, T., Field, T., Pickens, J., \& PelaezNogueras, M. (1996). Touch by intrusive and withdrawn mothers with depressive symptoms. Early Development and Parenting, 5, 111-115.

McLanahan, S. S., \& Carlson, M. J. (2002). Welfare reform, fertility, and father involvement. The Future of Our Children, 12, 147-163.

McLoyd, V. C. (1990). The impact of economic hardship on Black families and children: Psychological distress, parenting, and socioemotional development. Child Development, 61, 311-346.

Miller, C., \& Knox, V. (2001). The challenge of helping lowincome fathers support their children: Final lessons from Parents' Fair Share. NY: Manpower Research Development.

Miller-Loncar, C. L., Erwin, L. J., Landry, S. H., Smith, K. E., \& 
Swank, P. R. (1998). Characteristics of social support networks of low socioeconomic status African American, Anglo American, and Mexican American mothers of full term and preterm infants. Journal of Community Psychology, 26, 131-143.

O'Hara, M. W. (1986). Social support, life events, and depression during pregnancy and the puerperium. Archives of General Psychiatry, 43, 569-573.

Panzarine, S. (1986). Stressors, coping, and social supports of adolescent mothers. Journal of Adolescent Health Care, 7, 153161.

Panzarine, S., Slater, E., \& Sharps, P. (1995). Coping, social support, and depressive symptoms in adolescent mothers. Journal of Adolescent Health, 17, 113-119.

Pearson, T. L., Hunter, A. C., Ensminger, M. E., \& Kellam, S. G. (1990). Black grandmothers in multigenerational households: Diversity in family structural and parenting involvement in the Woodlawn community. Child Development, 61, 434-442.

Rhodes, J. E., Meyers, A. B., Davis, A. A., Ebert, L., \& Gee, C. B. (2003). The Social Support Network Questionnaire: A computer administered method for assessing social support and social strain. Manuscript submitted for publication.

Rhodes, J. E., \& Woods, M. (1995). Comfort and conflict in the relationships of pregnant, minority adolescents: Social support as a moderator of social strain. Journal of Community Psychology, 23, 74-84.

Rivara, F. P., Sweeny, P., \& Henderson, B. F. (1986). Black teenage fathers: What happens after the child is born? Pediatrics, 17, 151-158.

Rook, K. S. (1990). Parallels in the study of social support and social strain. Journal of Social and Clinical Psychology, 9, $118-132$.

Rook, K. S. (1998). Investigating the positive and negative sides of personal relationships: Through a lens darkly? In B. J. Spitzberg \& W. R. Cupach, (Eds.), The dark side of close relationships (pp. 369-393). Mahwah, NJ: Erlbaum.

Seidman, E., Allen, L., Aber, J. L., Mitchell, C., \& Feinman, J. (1994). The impact of school transition in early adolescence on the self-system and perceived social context of poor urban youth. Child Development, 65, 507-522.

Shapiro, J. R., \& Mangelsdorf, S. C. (1994). The determinants of parenting competence in adolescent mothers. Journal of Youth and Adolescence, 23, 621-641.

Snowden, L. (2001). Social embeddedness and psychological wellbeing among African Americans and Whites. American Journal of Community Psychology, 29, 519-536.

Spieker, S. J., \& Bensley, L. (1994). Roles of living arrangements and grandmother social support in adolescent mothering and infant attachment. Developmental Psychology, 30, 102-111.
Stack, C. (1974). All our kin: Strategies for survival in a Black community. New York: Harper \& Row.

Stevens, G., \& Cho, J. H. (1985). Socioeconomic indexes and the new 1980 census occupational classification scheme. Social Science Research, 14, 142-168.

Stier, H., \& Tienda, M. (1993). Are men marginal to the family? Insights from Chicago's inner city. In J. C. Hood (Ed.), Men, work, and family, (pp. 23-44). Newbury Park, CA: Sage.

Sullivan, M. (1989). Absent fathers in the inner city. Annals of the American Academy of Polictical and Social Sciences, 501, 4858.

Taylor, J., Henderson, D., \& Jackson, B. B. (1991). A holistic model for understanding and predicting depressive symptoms in African American women. Journal of Community Psychology, 19, 306-320.

Thompson, M. (1986). The influence of supportive relations on the psychological well-being of teenage mothers. Social Forces, 64, $1006-1024$.

Thompson, M., \& Peebles-Wilkins, W. (1992). The impact of formal, informal, and societal support networks on the psychological well-being of Black adolescent mothers. Social Work, 37, 322-328.

Tolson, T. F. J., \& Wilson, M. N. (1990). The impact of two- and three-generational black family structure on perceived family climate. Child Development, 61, 416-428.

Unger, D. G., \& Cooley, M. (1992). Partner and grandmother contact in Black and White teen parent families. Journal of Adolescent Health, 13, 546-552.

Unger, D. G., \& Wandersman, L. P. (1988). The relationship of family and partner support to the adjustment of adolescent mothers. Child Development, 59, 1056-1060.

Wasserman, G. A., Brunelli, S. A., \& Rauh, V. A. (1990). Social support and the living arrangements of adolescent and adult mothers. Journal of Adolescent Research, 5, 54-66.

Whitman, T. L., Borkowski, J. G., Keogh, D. A., \& Weed, K. (2001). Interwoven lives: Adolescent mothers and their children. Mahwah, NJ: Erlbaum.

Wilson, M. N., Greene-Bates, C., McKim, L., Simmons, F., Askew, T., Curry-El, J., \& Hinton, I. D. (1995). African American family life: The dynamics of interactions, relationships, and roles. In M. N. Wilson (Ed.), African American family life: Its structural and ecological aspects (pp. 5-21). San Francisco: Jossey Bass.

Received July 10, 2000

Revision received July 2, 2002

Accepted February 15, 2003

\section{E-Mail Notification of Your Latest Issue Online!}

Would you like to know when the next issue of your favorite APA journal will be available online? This service is now available to you. Sign up at http://watson.apa.org/ notify/ and you will be notified by e-mail when issues of interest to you become available! 